\title{
Formação permanente de professores e a educação ambiental crítica no contexto da escola pública
}

\section{Jorge Sobral da Silva Maia ${ }^{1}$}

1 Doutor em Educação para a Ciência. Professor do Programa da pós-graduação em Ciência Jurídica da Universidade Estadual do Norte do Paraná - UENP e do Programa da pós-graduação em Educação para a Ciência da Universidade Estadual Paulista UNESP - Bauru/SP, Brasil. E-mail: sobralmaia@uenp.edu.br

RESUMO: As diversas concepções do processo formativo de professores, tanto inicial quanto permanente podem ser consideradas na elaboração de estratégias para a inserção da educação ambiental na escola pública, uma vez que a transformação da sociedade rumo a um mundo sustentável e justo, em alguma medida, passa por esta instituição formadora de cidadania. Neste estudo discutimos estas concepções de forma crítica com vista a identificar fundamentos e práticas para a formação docente como educador ambiental em espaços formais de ensino, indicando caminhos para uma escola que, além da sustentabilidade, contribua com a transformação socioeconômica e ambiental, rumo a uma sociedade ambientalmente sustentável, socialmente justa e economicamente igualitária.

Palavras-chave: Escola pública. Formação de professores. Educação Ambiental Crítica. Sustentabilidade.

\section{Permanent formation of teachers and a critical environmental education in the context of the public school}

ABSTRACT: The diverse conceptions of the formative process of teachers, both initial and permanent, can be considered in the elaboration of strategies for the insertion of environmental education in the public school, since the transformation of society towards a sustainable and fair world, to some extent, passes by this institution that forms citizenship. In this study we discuss these conceptions critically in order to identify fundamentals and practices for teacher education as an environmental educator in formal educational spaces, indicating ways for a school that, in addition to sustainability, contributes to socioeconomic and environmental transformation, towards a society that is environmentally sustainable, fair socially and economically egalitarian

Keywords: Public school. Teacher training. Critical Environmental Education. Sustainability.

\section{INTRODUÇÃO}

Ao longo dos últimos 20 ou 30 anos foram implementadas diversas práticas relacionadas à inserção das questões ambientais na escola por meio de ações individuais de professores, por projetos da própria escola ou de instituições privada. Entretanto, verifica-se um avanço cabal de degradação socioambiental no Brasil e no mundo. Parece-nos que a causa 
deste insucesso pode estar ligada as práticas que orientam para "mudanças de comportamentos" ambientalmente inadequados, identificada como "adestramento ambiental"; como sinaliza Tozoni-Reis (2008) e Brügger (1994).

Também é importante considerar a crise metabólica própria do modo de produzir a vida em sociedade que gera desigualdades na distribuição das produções humanas de caráter material, econômico, social e intelectual. Fato que além de gerar problemas ambientais de toda ordem, impulsionam a precarização da vida humana em escala crescente no planeta.

Os fundamentos desta crise são apontados de maneiras diferentes, dependendo da compreensão histórico-social daquele que busca desvendar o intrigado conjunto de aspectos causais da problemática socioambiental contemporânea.

É comum os meios de divulgação escrito, redes sociais, redes televisivas tratarem da crise ambiental de forma difusa, concisa e, por vezes imprecisa, inviabilizando a compreensão necessária para o enfretamento responsável destas questões. Com isso, verifica-se que a população em geral e os tomadores de decisão em particular, não diferenciam claramente a intricada e complexa relação dos impactos das atividades humanas sobre a natureza, suas causas e consequências.

Como exemplo desta complexidade é possível citar as mudanças climáticas que segundo a "Organização Mundial de Saúde podem provocar 150 mil mortes todos os anos e ao menos cinco milhões de casos de doenças". (MARENGO, 2006, p. 135). Ainda, a intensificação do semi-árido do Nordeste brasileiro, eventos extremos de precipitação atmosférica nos grandes centros e aglomerados humanos, entre outros problemas, indicam a dimensão desta crise socioambiental atual.

Somem-se a estas problemáticas, questões como a desigualdade social, descomprometimento do poder público com o ambiente, baixo nível cultural da sociedade em geral e as diversas distorções das propostas de solução apresentadas pelos agentes públicos e por empresas privadas com interesses díspares que, como atores sociais, interferem e complexam ainda mais a situação.

Diante disto aparece a escola para viabilizar caminhos que permitam ampliar a compreensão da relação sociedade e natureza contribuindo, em alguma medida, com a solução do problema ambiental. Parece importante perguntar como isto ocorreu, ou como a escola surgiu como um dos elementos para o enfrentamento desta crise cuja dimensão é gigantesca?

Responder esta questão implica um trabalho hercúleo e não temos espaço para fazê-lo neste texto. Todavia, é possível, em tese, apontar algumas ideias que nos auxiliem a identificar fatores que tenham contribuído para este fato. A primeira está relacionada ao aspecto histórico da discussão ambiental, a segunda relaciona-se a educação ambiental e a terceira ao processo formativo do professor. Discutiremos brevemente cada uma delas a seguir.

\section{A PRIMEIRA IDEIA: ASPECTOS HISTÓRICOS DA DISCUSSÃO AMBIENTAL}

Qualquer marco civilizatório poderia ser tomado como ponto de partida para a relação 
humanidade e natureza. Optaremos aqui pelo processo histórico de superação do feudalismo e consequente ascensão do capitalismo de mercado. Este momento coincide com o advento da ciência moderna que amplia substancialmente a possibilidade de transformação da natureza em bens apropriáveis aos grupos humanos. Também com o avanço acelerado dos europeus em suas incursões pelo mundo em busca de riquezas e como explica Dorst (2008, p.31):

Ao estágio em que as destruições da natureza eram ainda circunscritas, sucedeu-se um período de dilapidações generalizadas; os recursos naturais de todo o planeta foram então saqueados para o benefício imediato dos pioneiros ou em proveito das nações colonizadoras, que praticavam nas novas terras uma economia de exportação.

No decurso dessa expansão acelerada dos povos europeus através do globo, múltiplas ondas humanas se sucederam na conquista de riquezas mundiais, cada uma delas trazendo novos contingentes de colonos, decididos a explorar a todo o custo as terras virgens ou imperfeitamente aproveitadas. 0 teatro dessa expansão foi inicialmente na América do Norte, onde a população branca data do século XVIII, em seguida a Austrália e a África, que, com a América do Sul constitui o continente mais recentemente devastado.

Esta expansão está diretamente associada ao domínio da técnica que se aprofunda neste momento histórico da humanidade, a descoberta de novos continentes e a possibilidade de explorar suas riquezas estimularam a avanço devastador da ação direta dos humanos sobre a natureza.

Estas condições eram potencializadas pela acumulação privada de capital e consequente aumento do mercado e do comércio exterior, fato relacionado ao crescimento das cidades e de seus mercados urbanos, da economia monetária, da propriedade senhorial, elevação do trabalho assalariado. (DOBB, 2009).

Neste momento inicia-se uma compreensão que se converterá em uma concepção ideológica hegemônica caracterizada pela ideia de acumulação como sinônimo de prosperidade e virtude. Era preciso enriquecer para ser digno. A superestrutura estava centrada nos dogmas religiosos da predestinação e nos fundamentos do protestantismo. (MAIA, et al, 2015). O que se verifica, portanto é a ideia geral de que era preciso produzir mais como um custo menor, aumentando a carga horária de trabalho e reduzindo o valor pago ao trabaIhador. Estes fatores estão na base dos processos que encadearam a chamada revolução industrial. Associa-se, neste sentido, e espoliação dos trabalhadores e a dilapidação do mundo natural.

Alguns autores como Weber (2004) em sua Ética protestante e o Espírito do Capitalismo, Marx (2007) em sua Ideologia alemã explicitam, ainda que por interpretações e concepções ideológicas distintas, elementos importantes para compreensão do anterior exposto e do desenvolvimento dos processos que, em alguma medida, elucidam detalhes históricos as ações humanas neste período e seus motivos.

Já no século XX com o advento do avanço da perspectiva capitalista, com as duas guerras mundiais inicia-se uma preocupação com as questões de ordem ambiental. Grün 
(2007) baseado em Worster (1992) afirma que o marco simbólico do início da ecologização das sociedades ocidentais deu-se no ano de 1945:

Em julho de 1945, no deserto de Los Alamos, Novo México, Estados Unidos, o azul do céu transformou-se subitamente em um clarão ofuscante. A equipe científica liderada pelo físico R. Oppenheimer explodia experimentalmente primeira bomba $\mathrm{H}$. Apenas dois meses depois eram jogadas as bombas atômicas sobre as populações civis de Hiroshima e Nagasaki. O Homo Sapiens (sic), esta espécie tardia surgida há pouco mais de um milhão e meio de anos, havia conquistado o poder de destruição total de si próprio e de todas as demais espécies sobre a face da Terra. Os seres humanos adquirem, então, a autoconsciência da possibilidade de destruição completa do planeta. Após o dia 6 de agosto de 1945 o mundo não seria mais o mesmo. (GRÜN, 2007, p. 16).

Na sequência deste momento Grün (op. cit) aponta o livro Silent spring de Carson (1962), publicado no Brasil pela Edições Melhoramentos, em que a autora discute as questões ecológicas motivada pelo uso de agrotóxicos na agricultura e suas implicações. Ainda os conservacionistas tendo por base as concepções de Malthus em seu Estudo sobre a população publicado em 1798 e David Ricardo em seus Princípios da Economia política e tributação, publicado em 1817 iniciam um significativo debate sobre a problemática ambiental e o crescimento populacional. Segundo Garcia e Priotto (2009, p. 55) os fundamentos de Malthus e Ricardo foram retomados "em particular por Keneth Boulding, Paul e Anne Ehrilch, Golmith (em O Manifesto pela sobrevivência) e Meadows (em os limites do crescimento)".

Os trabalhos destes autores vão dando forma crítica ao modo de como a vida vem sendo produzida em sociedade e, neste sentido, alimentam uma série de ações contra o modelo hegemônico existente. Inicia-se o que podemos chamar de movimento ecológico. (GRÜN, op. cit.).

Segundo Maia (2015a, p. 42) "em 1973, Maurice Strong e Ignacy Sachs formularam o conceito de ecodesenvolvimento com a intenção de gerar novos modos de produção, e talvez novos estilos de vida, de reconhecer as condições e as potencialidades ecológicas regionais.

Na década de 1980 a Organização das Nações Unidas elabora e publica o documento denominado Nosso futuro comum e propõem o Desenvolvimento sustentável. Conceito apropriado pela lógica do grande capital que o esvazia de conteúdo social mais preciso, contribuindo para consolidar as perspectivas analíticas e princípios políticos que tratam as questões ambientais e as suas respostas, desconsiderando as diferenças que caracterizam as sociedades atualmente. (MAIA, 2015a; FERNANDES, 2006).

Com base na concepção de desenvolvimento sustentável a ONU promove grandes conferências mundiais passando pela Conferencia das Nações Unidas para o desenvolvimento Sustentável e responsabilidade global a Rio ou Eco 92 e várias outras até Rio mais 20 no ano de 2012 em que se popularizou o conceito de economia verde que em nada muda o comprometimento com a lógica do grande capital em sua relação com a ambiente.

Fica cada vez mais claro que o sistema global imposto pelos governos baseia-se na manutenção da hegemonia do capital, na prioridade dos Estados em atender aos interesses 
econômicos das grandes corporações e de suas práticas destrutivas.

Em que pese todas estas considerações, alguns aspectos se mostraram pertinentes em relação às estratégias que este período trouxe para o debate ambiental no Brasil. Particularmente na Conferência das Nações Unidas para o desenvolvimento Sustentável e responsabilidade global em 1992 (ECO 92) dois documentos podem ser mencionados.

O primeiro de caráter oficial da Conferência foi a Agenda 21 que expressou o compromisso assumido por 179 países que participaram da ECO 92. Os temas tratados eram diversos e versavam sobre ambiente, saneamento, habitação, saúde, educação, ainda a pobreza, a biodiversidade entre outros também significativos. Tratava do papel dos vários agentes sociais, suas ações e propostas. Envolveu governos, instituições privadas, cientistas, indígenas, sindicatos e como isso, buscava fornecer os subsídios norteadores de princípios para melhorar as condições de vida das populações e de seus ambientes com vista ao desenvolvimento sustentável.

Paralelo a Conferência ocorreu o encontro da Sociedade civil denominado Fórum Global das organizações não governamentais que, entre diversos documentos deram existência ao Tratado de educação ambiental para sociedades sustentáveis e responsabilidade global, um documento significativo na elaboração da Política Nacional de Educação ambiental (PNEA) - Lei 9795 de 1999. Este tratado apresenta 16 princípios para a sociedade sustentável e responsabilidade global que vão da educação como um direito de todos até a educação ambiental como promotora de uma consciência ética em relação a todas as formas de vida na Terra, impondo limites as ações humanas sobre estes seres e seus ciclos vitais.

Segundo Tozoni-Reis (2007) é evidente a inspiração no pensamento de Paulo Freire presente no Tratado das ONGs e argumenta que

A concepção de educação e a proposta pedagógica que dela emerge são marcadas por conceitos básicos de construção da pedagogia libertadora: transformação social, conscientização, educação política, cooperação e diálogo. Além disso, os temas ali expressos são temas que, na pedagogia Paulo Freire, são problematizadores para o processo de conscientização política e transformador como: pobreza, a degradação humana e ambiental, a violência, a compreensão das formas de vida da população, suas condições de saúde, a fome e, em especial a democracia. (TOZONI-REIS, 2007, p. 207).

Os fundamentos freirianos presentes no documento em questão demonstram o forte interesse pela valorização dos saberes universais populares e a busca da emancipação humana como condição para a solução da crise ambiental naquele período da história da humanidade.

É preciso considerar que estas proposições, tanto da Agenda 21, quanto do Tratado das ONGs foram pouco implementadas, apesar do esforço de muitos profissionais, ambientalistas ou não que diuturnamente lutaram e lutam pela busca da justiça social e do cuidado com a vida em geral no planeta.

Uma evidencia do esforço empreendido está em que os fundamentos da concepção pedagógica de Paulo Freire, em alguma medida, vão orientar ainda que de forma contraditória os princípios da PNEA de 1999. Contradição é evidenciada por Janke (2012) em seus estudos sobre esta política e conclui que a Lei 9795/99, que instituiu a Política Nacional de 
Educação Ambiental no Brasil, é instrumento político determinante para que as políticas públicas de educação ambiental no Brasil configurem-se num campo em disputa.

Somente por meio do decreto no 4.281, de 25 de junho de 2002 a PNEA é regulamentada e fica a cargo, segundo o artigo 1, "dos órgãos e entidades integrantes do Sistema Nacional de Meio Ambiente - SISNAMA, pelas instituições educacionais públicas e privadas dos sistemas de ensino, pelos órgãos públicos da União, Estados, Distrito Federal e Municípios, envolvendo entidades não governamentais, entidades de classe, meios de comunicação e demais segmentos da sociedade." (BRASIL, 2002).

O decreto também cria o órgão gestor que fica responsável pela coordenação da PNEA que responde, pelo decreto, ao Ministério do Meio ambiente e o da Educação.

Ainda no âmbito legal convém citar a Resolução $\mathrm{n}^{0}$ 02, de 15 de Junho de 2012 que estabelece as Diretrizes Curriculares Nacionais para a Educação Ambiental (DCNEA) que propõe, corroborando a PNEA, a promoção da Educação ambiental em todos os níveis da educação formal no Brasil.

Estes processos vão firmar a responsabilidade da escola na inserção da educação ambiental em suas realidades. A grande questão é qual educação ambiental? Refletimos sobre esta problemática a seguir em uma perspectiva crítico-dialética, com vista a discutir uma concepção de educação ambiental para além dos documentos oficiais, buscando outros caminhos para a politização do debate ambiental, que contribua para integrar cultura, economia, política, educação no sentido da práxis transformadora qualificando as relações socioecológicas para superar a reprodução das relações alienadas que mercantilizam a natureza.

\section{A SEGUNDA IDEIA: A EDUCAÇÃO AMBIENTAL}

Consideramos que a educação ambiental não é uma entidade autônoma, existente por si, mas é fruto de um processo histórico, cujas bases expusemos de forma muito geral no item anterior. (MAIA, 2015a). Conceitualmente a educação ambiental é, antes de tudo, educação. Todavia, ela guarda uma especificidade que a define. Esta especificidade é o ambiente. Neste sentido, pode-se caracterizá-la como um processo educativo que tematiza o ambiente.

Para esclarecer o conceito entende-se importante delimitar o ato educativo, bem como, o entendimento de ambiente, uma vez que são concepções carregadas de sentido. Compreende-se o processo educativo ou o trabalho educativo como o

Ato de produzir direta e intencionalmente em cada indivíduo singular a humanidade que produzida historicamente e coletivamente pelo conjunto homens. Assim, o objeto da educação diz respeito, de um lado, à identificação dos elementos culturais que precisam ser assimilados pelos indivíduos da espécie humana para que se tornem humanos e, de outro lado e concomitantemente, à descoberta das formas mais adequadas para atingir esse objetivo. (SAVIANI, 2005, p.13).

O autor ainda defende que é preciso, ao se identificar quais os elementos culturais que 
necessitam ser assimilados, destacar o essencial, o principal ou o fundamental neste universo de conhecimentos já produzidos pela humanidade. Ainda evidencia a necessidade da organização dos meios e modos, pelos quais cada indivíduo possa realizar para si a humanidade produzida historicamente pelo conjunto da sociedade (p. 14).

Do ponto de vista da educação ambiental cabe nos perguntar o que é essencial, principal ou fundamental e quais as formas mais adequadas para desenvolver esse trabalho pedagógico.

Uma possível resposta, ainda que não definitiva, implica em compreender o caráter eminentemente crítico da Educação ambiental que visa, a princípio, superar práticas educativas e pedagógicas pautadas na apropriação distorcida, simplificadora e reducionista dos, muitas vezes, agentes causadores dos problemas ambientais que observamos hoje. (MAIA; TEIXEIRA, 2015, p. 294).

A afirmação anterior conduz à reflexão de que abordagens não críticas e críticoreprodutivistas precisam ser superadas, uma vez que estas concepções possibilitam práticas educativas superficiais e de senso comum que permeiam o currículo, uma vez que não se configuram como síntese de múltiplas determinações (SAVIANI, 2005). Este é um dos grandes desafios da educação ambiental crítica no espaço escolar:

Neste ponto surge o grande problema e desafio para a EA crítica da forma como a compreendemos: seus princípios devem pautar-se em ações que contribuem para superação do modo produção capitalista, principal causador dos problemas ambientais, segundo nossa interpretação. Nesse sentido, é importante destacar que as práticas educativas ambientais da vertente histórico crítica, que se esforçam para implementar um processo educativo que empreende uma reflexão crítica sobre a realidade objetiva, configuram-se numa proposta formativa que contribui para promover o desenvolvimento da consciência filosófica, demanda legítima e necessária ao processo educativo escolar. (MAIA; TEIXEIRA, 2015, p. 294)

Desenvolver a consciência filosófica, como propõe os autores implica em que o professor educador ambiental pode considerar que não há fórmulas ou receitas prontas, entretanto pode partir de alguns aspectos que lhe permite elaborar concepções teóricas e práticas para realização da educação ambiental crítica na escola. O primeiro aspecto relacionase com identificar quem é seu público alvo, a quem ele precisa ensinar. O segundo aspecto é verificar o que será ensinado. Em um terceiro momento questionar quem ensina, um processo de se conhecer como professor e como educador ambiental e em seguida, na próxima etapa, identificar as condições materiais e estruturais que dispõe para realizar sua pratica pedagógica.

Em posse dos elementos obtidos após o reconhecimento dos quatro aspectos citados, o professor educador ambiental, de forma intencional, pode elaborar estratégias que possibilitam qualificar a prática social dos estudantes e a dele próprio. Compreende-se aqui a prática social como o momento inicial do processo educativo

Neste primeiro momento, o professor tem uma "síntese precária", pois há conhecimento e experiências em relação à prática social, mas seu conhecimento é limitado, pois ele ainda não tem claro o ní- 
vel de compreensão dos seus alunos. Por sua vez, a compreensão dos alunos é sincrética, fragmentada, sem a visão das relações que formam a totalidade. O primeiro momento do método articula-se como o nível de desenvolvimento efetivo do aluno, tendo em vista adequação do ensino aos conhecimentos já apropriados e ao desenvolvimento iminente, no qual o ensino deve atuar. Com isso se quer dizer que esse momento deve, com base nas demandas da prática social (o que não é sinônimo de demandas do cotidiano), selecionar conhecimentos historicamente construídos que devam ser transmitidos, traduzidos em saber escolar. 0 ponto de partida da prática educativa é a busca pela apropriação, por parte dos alunos, das objetivações humanas (MARSIGLIA, 2011, pp. 23-24. Parênteses da autora e grifos nossos).

Esta abordagem permite identificar as questões próprias da prática social gerando condições para sua problematização. Contudo, cabe esclarecer que a base para problematizar a prática social necessita de conceitos sistematizados que possibilitem demonstrar os processos em sua totalidade e complexidade indo além da simples compreensão cotidiana dos fenômenos.

Os conceitos sistematizados já foram apropriados pelo professor ao longo do seu processo formativo, fato que lhe confere a condição de portador de signos, ou dos instrumentos psíquicos produzidos ao longo do processo formativo humano, que lhe permite agir sobre os fenômenos psicológicos para produzir modificações que levam às ações mais qualificadas dos seres humanos em suas relações com o mundo.

Desta forma a inteligibilidade acerca da realidade está intimamente associada ao desenvolvimento histórico social dos seres humanos, desenvolvimento este atrelado a processos mentais originando um psiquismo sofisticado, (MARTINS, 2011). O anterior exposto implica em entender que o "Psiquismo é a unidade material e ideal expressa na subjetivação do objetivo, isto é, na construção da imagem subjetiva do mundo objetivo. É material na medida em que é estrutura orgânica e é ideal posto ser o reflexo da realidade, a ideia que a representa subjetivamente." (MARTINS, 2011, p. 45).

Ao considerarmos o psiquismo como descrito pela autora como sofisticado queremos dizer que "expressa-se no estabelecimento de conexões entre os fenômenos da realidade e entre suas propriedades e características" (MARTINS, 2011, p. 49). É de fato o pensamento teórico.

É o pensamento teórico que dá ao professor a condição de problematizar a prática social de seus estudantes e ao mesmo tempo, nesta ação, problematizar a sua própria prática, isto é, identificar os principais problemas postos pela prática social que se articulam com o conhecimento a ser ensinado pelo professor e assimilado pelos estudantes.

Neste processo os estudantes vão apropriando as ferramentas teóricas e práticas para analisar e propor alternativas aos problemas apresentados. Saviani (2012) denomina este momento do ato pedagógico de instrumentalização e, ainda previne que para não o entender em sentido tecnicista, mas como "a apropriação pelas camadas populares das ferramentas culturais necessárias à luta social que travam diuturnamente para se libertar das condições de exploração em que vivem". (p.71).

A relação orgânica entre a prática social, a problematização e a instrumentalização produzida intencionalmente pelo professor permite a incorporação dos instrumentos cultu- 
rais, convertidos agora em elementos ativos da transformação social (SAVIANI, op. cit.). Esta é concepção de educação que consideramos adequada para caracterizar o elemento educativo da educação ambiental.

Esta concepção de educação implica em compreender o ambiente também na perspectiva crítica, emancipatória e transformadora.

Partimos da ideia que o ambiente é fonte de manutenção da vida em toda a sua plenitude, entretanto é fundamental considerar para, além do culto ao mundo natural como defendem conservacionistas radicais, a concepção de ambiente como uma categoria social.

A opção por esta concepção justifica-se pelos

[...] progressivos conflitos ecológicos distributivos e de uso inerentes ao processo de acumulação capitalista, que faz com que determinados grupos sociais sejam privados do acesso aos recursos e serviços ambientais e com que o ritmo de destruição das condições ecológicas necessárias para uma vida digna. (LOUREIRO et. al., 2009, p. 83).

A discussão ambiental necessita considerar o ambiente com local de disputas entre racionalidades e intencionalidades distintas em constante conflito pela apropriação do patrimônio ambiental. O modelo civilizatório atual atende cada vez mais aos interesses privados em detrimento do coletivo, fato que implica que o poder econômico, além de controlar o poder político, traz para si os benefícios ambientais em detrimento da maioria da população que fica alijada dos fatores significativos para a sua qualidade de vida.

Esclarecer esta temática e formar indivíduos que o compreendam e, se posicionem de forma a mudar essa realidade e o modelo civilizatório predatório e injusto está na dinâmica do processo educativo crítico ambiental e, portanto da escola que se proponha sustentável. Consideramos este processo no item a seguir.

\section{A TERCEIRA IDEIA: O PROCESSO FORMATIVO DO PROFESSOR}

Os professores são agentes fundamentais na construção da sociedade e também importantes formadores de condições precisas para transformá-la rumo à justiça social, a emancipação política e humana. Entretanto, para que possam se comprometer com essa transformação necessitam estar instrumentalizados com as mais elevadas ferramentas culturais que lhes permitam aprofundar a compreensão do modo de produzir a vida em sociedade, reconhecer a história de seu surgimento e os mecanismos e processos que a mantém em funcionamento.

Evidentemente que estas ferramentas são os conhecimentos científicos, artísticos, filosóficos e culturais produzidos pela humanidade em sua constituição ao longo do tempo. Também conhecer e aplicar os fundamentos psicológicos e pedagógicos atinentes a realidade que os cerca, fato que implica não somente identificar e reconhecer os problemas da comunidade, mas conhecer aqueles que, em sua trajetória, deverão formar.

Também cabe ao professor entender que seu papel está no ato educativo e, portanto 
seu problema e objetivo de trabalho é o processo de ensino e aprendizagem. Consiste em estabelecer intencionalmente os objetivos de ensino e de os objetivos de aprendizagem para uma formação integral e consistente de seus aprendizes.

Ao considerarmos o exposto segundo a especificidade da educação ambiental, podemos intuir que não cabe ao professor buscar resolver problemas ambientais sejam eles da escola ou da comunidade que o cerca. Se assim o proceder, o professor educador ambiental atuará como um indivíduo apenas prático e abrirá mão do sentido pedagógico de sua profissão, que no caso da educação ambiental, implica em tematizar o ambiente por meio da práxis transformadora que entendemos como a relação entre teoria e prática.

Muitos estudos demonstram que a educação ambiental está na escola, por exemplo, o Censo Escolar de 2001 que evidenciou que mais de 60\% das escolas brasileiras incluem, de alguma maneira, a educação ambiental em suas atividades e em 2004 este percentual superou os 90\%. Também um estudo realizado por Trajber e Mendonça (2006) identificou que a inserção da educação ambiental se realizava por meio de projetos de ensino com origem nas atividades da própria escola, por seus professores ou de agentes de fora da escola, principalmente instituições privadas interessadas em vender suas ideias e produtos com dizeres de cumprir seu papel com a responsabilidade ambiental.

Ora pelo exposto pode-se deduzir que a educação ambiental esta na escola. Entretanto porque esta instituição ainda não é sustentável? A explicação pode estar na tese de Tozoni-Reis e Campos (2015) que considera esta larga inserção da educação ambiental na educação básica como uma inserção fragilizada e afirmam:

Nossa maior preocupação com a fragilidade da inserção da educação ambiental nas escolas, bastante presente em nossos estudos, diz respeito a forma como pensamos essa inserção. Neste e em outros estudos temos nos posicionados de forma radical a favor da inserção da educação ambiental nos currículos escolares, isto é, compreendemos que ela terá importância necessária a formação ambiental dos sujeitos educandos se, e somente se, se inserir como "atividade nuclear do currículo" [...] (TOZONI-REIS; CAMPOS, 2015, p. 108, itálico e aspas das autoras).

A ideia de atividade nuclear as autoras buscam em Saviani (2005) que expõe a atividade nuclear como aquela que é fundamental e indispensável ao processo de ensino e aprendizagem e a atividade secundária como o conjunto de atividades complementares ao currículo. Parece-nos que as autoras identificam a superação da fragilidade da Educação ambiental na escola colocando-a, não mais por meio de projetos de cunho prático utilitários, mas como componente do currículo, tornando-a atividade nuclear.

Esta tese implica em alguns problemas para o contexto atual de organização dos currículos e da lógica de funcionamento da escola, bem como do processo formativo do professor. Isto porque a educação ambiental precisa estar presente de forma transversal e interdisciplinar e, em geral a escola está organizada de forma disciplinar e o processo formativo do professor também.

Compreendemos, diante da realidade que se apresenta que para construirmos uma escola sustentável parece necessário rever a organização escolar, superar a o pensamento disciplinar potencializando o diálogo entre professores, estudantes e gestores consideran- 
do o papel da escola como formadora de cidadania. Também são necessários processos de inserção da educação ambiental como tema nuclear nos currículos e para os professores atuantes o contato com os estudos mais avançados em termos pedagógicos e psicológicos relacionados à realidade brasileira, tanto regional como local.

Somente uma formação permanente e comprometida com a qualidade de vida poderá contribuir com a estruturação de escolas sustentáveis, muito mais por princípios éticos do que por imposições normativas em um momento que os problemas socioambientais alcançam uma alarmante dimensão planetária indicando uma crise da civilização espantosa que evidencia que modelo civilizacional não deu certo, pelo menos para a maioria da população mundial que vive sob condições precárias e limitantes das potencialidades humanas na construção da emancipação dos seres humanos na Terra.

\section{CONSIDERAÇÕES FINAIS}

Iniciamos nossa discussão refletindo sobre a educação ambiental e os fundamentos históricos da problemática ambiental. Delimitamos como marco civilizatório para este texto a transição do mundo feudal para capitalismo mercantil e avançamos pelos processos da evolução da técnica e seus usos para entendermos a crise contemporânea. Buscamos identificar como a escola surgiu como uma das instituições significativas para lidar com essa crise e nos apoiamos nos fundamentos histórico-crítico para compreender a educação ambiental em sua vertente emancipátoria, o que implicou em considerar o ambiente como uma categoria social.

Este caminho nos conduziu para reflexões que identificaram a práxis, em linhas gerais, como a estratégia para que o professor educador ambiental não se limite a prática simples e pura que pode descaracterizar seu papel formador, evidenciando a necessidade do aprofundamento teórico para qualificar seu papel de formador de cidadania.

Apontamos a fragilidade da inserção da educação ambiental na escola e esclarecemos a importância desta ser tema nuclear no currículo, com vistas a superar a perspectiva disciplinar na organização da escola e na busca da interdisciplinaridade que é inerente a educação ambiental.

Chamamos atenção para esses agentes limitadores da instituição da escola sustentável que entendermos ser aquela ocupada, mais com princípios éticos, do que normativos em que o processo pedagógico esteja sustentado no reconhecimento da pratica social da comunidade escolar, qualificando-a para conduzir à emancipação tanto política quanto humana daqueles que ali atuam.

Nesse sentido é relevante considerar que o consenso em torno da educação ambiental precisa ser problematizado, identificando as contradições e interesses diversos no âmbito das políticas e instituições públicas e seus agentes e os da sociedade civil em que disputam os grupos sociais, intensificando a exploração do patrimônio ambiental e social. Isto que dizer que há diferentes intenções segundo os fundamentos ideológicos dos indivíduos e instituições. Precisamos reconhecer qual o nosso papel, ou estamos junto aos agentes que vêem dilapidando o ambiente para acúmulo privado, ou ao lado daqueles que diuturna- 
mente lutam por uma vida mais digna e por uma sociedade mais justa. Assumir este compromisso é a base para nós professores construirmos a escola sustentável no século XXI.

\section{REFERÊNCIAS}

BRASIL. Presidência da Republica Casa Civil. DECRETO no 4.281, de 25 de junho de 2002. Subchefia de Assuntos Jurídicos.

BRÜGGER, Paula. Educação ou adestramento ambiental? Florianópolis: Letras Contemporâneas, 1994.

DOBB, Maurice. A evolução do capitalismo. Rio de Janeiro: LTC, 2009.

DORST, Jean. Antes que a natureza morra: por uma política ecológica. $8^{\underline{a}}$ reimpressão. São Paulo: Edgar Blucher, 2008.

FERNANDES, M. Desenvolvimento sustentável: antinomias de um conceito in FERNANDES, M.; GUERRA, L. (orgs) Contra o discurso do desenvolvimento sustentável. 2ed Belém: Associação de Universidades da Amazônia, Universidade Federal do Pará, Núcleos de Altos Estudos Amazônicos, 2006.

GARCÍA, Daniela Soledad; PRIOTTO, Guillermo. Educacíon ambiental: aportes políticos y pedagógicos en La construcción del campo de La educacíon ambiental. 1 ed. Buenos Aires: Jefatura de Gabinete de Ministros - Presidencia de la Nacion - Desarollo sustentable, 2009.

GRÜN, Mauro. Ética e educação ambiental: a conexão necessária. 11 ed. Campinas/SP: Papirus Editora, 2007.

JANKE, Nadja. Política Nacional de Educação Ambiental: contradições e disputas, 2012224 f.: il. Tese (Doutorado)-Universidade Estadual Paulista. Faculdade de Ciências, Bauru, 2012. LOUREIRO, Carlos F. B. et. al. Os vários ecologismos dos pobre e as relações de dominação no campo ambiental. In LOUREIRO, Carlos F. B. (org.), et. al. Repensar a educação ambiental: um olhar crítico. São Paulo: Cortez, 2009.

MAIA, Jorge Sobral da Silva et all. Educação ambiental como campo de disputas: a necessária discussão epistemológica. Planeta Amazônia: Revista Internacional de Direito Ambiental e Políticas Públicas. Macapá, n. 7, p. 75-87, 2015.

MAIA, Jorge Sobral da Silva. Educação ambiental crítica e formação de professores. 1 ed. Curitiba: Appris, 2015 a.

MAIA, Jorge Sobral da Silva; TEIXEIRA, Lucas André. Formação de professores e educação ambiental na escola pública: contribuições da pedagogia histórico-crítica. Revista HISTEDBR On-line, Campinas, no 63, p. 293-305, jun2015.

MARSIGLIA, Ana Carolina. G. A prática pedagógica histórico-crítica na educação infantil e ensino fundamental. Campinas/SP: Autores Associados, 2011.

MARENGO, José A. Mudanças climáticas globais e seus efeitos sobre a biodiversidade: caracterização do clima atual e definição das alterações climáticas para o território brasileiro ao longo do século XXI. Brasília: MMA, 2006.

MARX, Karl. A Ideologia Alemã. São Paulo: Boitempo, 2007.

MARTINS, Lígia Márcia. Pedagogia histórico-crítica e psicologia histórico-cultural. In MAR- 
SIGLIA Ana Carolina G. (orgs) Pedagogia histórico crítica: 30 anos. Campinas/SP: Autores Associados, 2011.

SAVIANI, Dermeval. Pedagogia histórico-crítica: primeiras aproximações. 9 ed. Campinas/SP: Autores Associados. 2005.

TOZONI-REIS, Marília F. de C.; CAMPOS, Luciana M. L. A formação inicial de professores no fortalecimento da educação ambiental escolar: contribuições da pedagogia históricocrítica. In LOUREIRO, C. F. B.; LAMOSA, R. de A. C. Educação ambiental no contexto escolar: um balanço da década da educação para o desenvolvimento sustentável. Rio de Janeiro: Quartet: CNPq, 2015.

TOZONI-REIS, Marília Freitas de Campos. Pesquisa-ação em Educação Ambiental. Pesquisa em Educação Ambiental, vol. 3, n. 1 - pp. 155-169, 2008.

TOZONI-REIS, Marília Freitas de Campos. Contribuições para uma pedagogia crítica na educação ambiental: reflexões teóricas. In LOUREIRO, Carlos F. B. (org.) et. al. A questão ambiental no pensamento crítico: natureza, trabalho e educação. Rio de Janeiro: Quartet, 2007.

TRAJBER, R.; MENDONÇA, P. (org.) Educação na diversidade: o que fazem as escolas que dizem que fazem educação ambiental. Brasília: Secretaria de Educação continuada, Alfabetização e Diversidade, 2006.

WEBER, Max. A ética protestante e o Espírito do capitalismo. São Paulo: Cia da Letras, 2004.

WORSTER, Donald. Nature's economy: a history of ecological ideas. New York: Cambridge, 1992. 